\title{
0 leitor como ausência constitutiva de sentido no Jornalismo: a reorganização do discurso jornalístico no hipertexto digital
}

\section{Laura Strelow Storch}

\section{Resumo}

0 presente texto busca discutir a reorganização

do discurso jornalístico considerando um processo

de materialização da leitura ativa no jornalismo

digital, a partir do hipertexto. Buscamos

considerar, ainda, as implicações discursivas da

leitura enquanto função do discurso, que se afirma

em um movimento dialógico de atribuição de

sentido ao texto. Partindo de um breve panorama

da posição do leitor na dialética de construção

do texto jornalístico e ponderando a inscrição de

novas lógicas textuais advindas da programação

hipertextual na web, pretende-se debater as

formas de manifestação das atividades de leitura,

salientes na estrutura jornalística digital.

Palavras-chave

Jornalismo. Hipertexto. Leitura. Interação.
Laura Strelow Storch | Isstorch@gmail.com

Jornalista, doutoranda em Comunicação e Informação pela Universidade Federal do Rio Grande do Sul - UFRGS.

\section{Introdução}

0 desenvolvimento de ferramentas de participação e colaboração em diversos ambientes da Web tem modificado as formas de circulação de informações e, mesmo, os modelos de comunicação. 0 jornalismo desenvolvido na rede se submete a uma nova estrutura de linguagem, o hipertexto, e também sofre modificações: passa a oferecer aos leitores oportunidades de participação, debate e colaboração, de forma a transformar a rotina de profissionais e de organizações que buscam manter seu espaço na nova mídia.

Como o jornalismo é uma forma de discurso que constitui um tipo de conhecimento sobre o mundo e o cotidiano, e considerando-se as dinâmicas de constituição desse discurso a partir das negociações de sentido entre jornal/ jornalista e leitores, busca-se, aqui, refletir sobre os processos de adaptação narrativa da prática jornalística à rede - especialmente no que se refere à linguagem hipertextual - e às exigências das organizações de comunicação às quais os veículos online se subordinam. 
Deve-se levar em conta, neste contexto, que as características dos ambientes digitais conectados em escala global e as complexas negociações que resultam no produto jornalístico, além das influências das rotinas de socialização da rede, podem levar a reformulações do próprio modelo de jornalismo na web. Por isso, procura-se discutir as manifestações de atividades de leitura no jornalismo digital, salientando os aspectos principais de sua adaptação aos sistemas e ambientes que formam a comunicação online.

\section{Atividades de leitura na (hiper) textualidade}

É razoável, entre outras possibilidades, entender o texto como um objeto comunicacional, ou seja, como um objeto que define reações enunciativas, atribui funções e inscreve marcas para a interpretação. Ao partir desse ponto de vista, percebe-se 0 texto como uma plataforma de atividades entre sujeitos, na qual os processos de significação e compreensão se realizam. Os discursos são entendidos como realizações sociais coletivas, elaboradas a partir de atividades de linguagem ${ }^{1}$ desenvolvidas no cotidiano social entre sujeitos de linguagem historicamente situados. Essas configurações se organizam em torno de certas regras subjetivas de funcionamento que, de forma mais específica, definem quem, o que e como os discursos são anunciados.

Seguindo esses pressupostos, pode-se perceber a existência de vários textos, tipos diferentes de manifestações sociais racionais, elaboradas a partir de critérios exteriores e anteriores, que os sustentam e os diferenciam. Cada texto, em sua época, através das exigências materiais e linguísticas a eles associadas, formam, enfim, diferentes leitores.

$$
\begin{aligned}
& \text { Não há leitores para os ditos textos teóricos, aca- } \\
& \text { dêmicos ou dissertativos. A questão, portanto, é } \\
& \text { saber como acontece, no contexto universitário } \\
& \text { contemporâneo, a construção do leitor com o } \\
& \text { perfil adequado aos circuitos de circulação do } \\
& \text { saber. } 0 \text { modo como está aqui formulado esse } \\
& \text { problema sugere que se tome a perspectiva da } \\
& \text { constituição de subjetividades [...]. Adotar esse } \\
& \text { ponto de vista significa conceber, de saída, o lei- } \\
& \text { tor como uma posição de sujeito historicamente } \\
& \text { determinada (SOUZA, 2003, p. 129). }
\end{aligned}
$$

Ao propor a compreensão da construção de um perfil de leitor (no caso, o acadêmico), Souza adverte para uma dissociação entre 0 discurso em si e as leituras possíveis sobre ele. Pode-se pensar que essa dissociação se elabora, de forma mais ampla, em dois contextos específicos, ainda que indissociáveis: o primeiro relaciona-se

Baseado na psicologia da linguagem de Vigotsky e com inscrição no interacionismo, o conceito discutido por Bronckart (1999) destaca que a linguagem é o instrumento primeiro de socialização, e que é da interação social que se formulam as capacidades conscientes de racionalização.

A ordem dos discursos de Foucault (2004) apresenta uma tripla dinâmica - poder, acontecimento e funcionamento - como categorias observáveis mais gerais para o controle dos discursos. São princípios de exclusão, ora do sujeito, ora do objeto do discurso, baseados no que o autor denomina "vontade de verdade"; além disso, são princípios de controle e validação sobre sua aparição; e, por fim, condições de seu funcionamento, como ritos, sistemas e os sujeitos que falam. 
aos movimentos de "construção" discursiva do sujeito leitor e envolve diretamente categorias de funcionamento do discurso ${ }^{2}$, como aquelas propostas por Foucault (2004); o segundo envolve mais especificamente o processo cognitivo de significação dos discursos, o momento de atribuição de sentido ao texto.

Na perspectiva proposta por Foucault sobre a ordem dos discursos, em especial o panorama traçado sobre seu funcionamento e sua materialidade, percebe-se a ação concreta das estruturas de controle dos discursos. A fim de garantir a manutenção da ordem dos discursos, há que se garantir, primeiramente, que 0 acesso a eles seja qualificado: uma disjunção dos sujeitos que falam. Foucault destaca que

[...] nem todas as regiões do discurso são igualmente penetráveis; algumas são altamente proibidas (diferenciadas e diferenciantes), enquanto outras parecem estar quase abertas a todos os ventos e postas, sem restrição prévia, à disposição de cada sujeito que fala (2004, p. 37).

A crítica, a criação, a capacidade de inscrever 0 discurso em movimentos de vontade de verdade, a referência a eles, as formas de circulação dos textos em determinado contexto discursivo, os ritos que qualificam os indivíduos que falam esses procedimentos (e tantos outros) visam definir os gestos, comportamentos e todo um conjunto de signos que vão acompanhar 0 discurso. Fixam, enfim, "a eficácia suposta ou imposta das palavras, seu efeito sobre aqueles aos quais se dirigem, os limites de seu valor de coerção" (FOUCAULT, 2004, p. 39).

Os mecanismos de controle dos discursos passam a agir em um contexto de "treinamento de leitura", indicando, avaliando, sugerindo, criticando os modelos de leitura que se configuram ao redor de seus textos. Se os discursos buscam certo perfil de leitores, é necessário também que certos contextos sóciohistóricos auxiliem na sua formação, de forma que serão condições de leitura tanto os suportes, a língua, os hábitos, quanto, e especialmente, os ritos, os sistemas de validação da leitura.
A leitura é sempre apropriação, invenção, pro- dução de significados [...]. Toda história da lei- tura supõe, em seu princípio, essa liberdade do leitor que desloca e subverte aquilo que o livro Ihe pretende impor. Mas essa liberdade leitora não é jamais absoluta. Ela é cercada por limita- ções derivadas das capacidades, convenções e hábitos que caracterizam, em suas diferenças, as práticas de leitura. 0s gestos mudam segun- do os tempos e lugares, os objetos lidos e as razões de ler. Novas atitudes são inventadas, outras se extinguem (CHARTIER, 1999, p. 77).

0 ato de ler passa a ser entendido como um gesto de interpretação situado entre condições técnicas e rituais discursivos específicos, organizados historicamente e dependentes das atividades de linguagem, das trocas, apropriações e subversões dos leitores - portanto, mutáveis. No jogo complexo dos discursos, as atividades de linguagem representam a configuração do segundo contexto de dissociação das formas de leitura e do discurso em si: é na materialidade de 
um lugar de ausência, reflexo do efeito dialógico constituidor dos discursos, que o leitor assume sua função.

0 efeito (ou lugar) de ausência surge pela exigência interna do texto (acadêmico ou jornalístico, por exemplo) de uma determinada posição de leitor, fora da qual não se produzem ou reproduzem leituras e escritas, sejam elas destinadas a alimentar a construção do saber (textos acadêmicos) ou, no caso do texto jornalístico, o conhecimento sobre o mundo cotidiano. A ausência está, assim, no sentido, e o leitor é a função vazia do discurso exatamente por ser aquele que lhe atribui sentido.

Como salienta Souza, "interpretar é uma ordem mais ampla de ação, uma lei que, abrigando atos de leitura, intervém na relação sujeito e sentido" (2003, p. 135), ou seja, o alguém para o qual o texto se direciona - ausente na constituição dos enunciados porque desconhecido - se torna parte da relação aberta da construção discursiva ao se instituir leitor. Sua função passa a ser, na interpretação, realizar o texto.

De uma forma geral, os discursos enquanto ato de escritura procuram definir os ditames de uma boa leitura, sem se perguntar quem é o leitor pressuposto nessa atividade. 0 lugar dessa figura está vazio e é o seu preenchimento, mediante a relação dos textos com a sua exterioridade, que fará emergir o perfil do leitor (SOUZA, 2003, p. 136).

Assim, ao ler, o sujeito leitor completa o circuito do discurso (pelo menos no contexto específico daquele texto) e registra a materialização do lugar de ausência. Mas, a partir disso, deve-se considerar que 0 horizonte de leituras também se completa, ou seja, acontece uma "exclusão das outras formas de ler, portanto de outro sujeito leitor" (SOUZA, 2003, p. 135).

Cada leitor preenche o discurso a partir de sua leitura e, desta forma, encerra as demais possibilidades de ler, os outros gestos de leitura. A constituição dos discursos, nestes casos, passa a depender de diferentes atividades de linguagem, de contextos distintos do texto em si, para a sua consolidação enquanto formação discursiva.

Com a web, começa-se a reconsiderar essas questões, percebendo-se uma materialização dos processos de escrita e leitura em conjunto. Mesmo as noções de escritura, leitura e autoria se tornam mais complexas e, muitas vezes, indiferenciáveis no contexto hipertextual. A elaboração cognitiva da interpretação, como destacada aqui, se mantém, e mesmo se complexifica em virtude das exigências da leitura hipertextual no universo virtual. Mas pode-se perceber um processo de concretização de fenômenos apenas subjetivamente observáveis nos demais suportes de comunicação: a leitura pode se tornar uma atividade materialmente situada, de forma que as marcas de interpretação passam a constituir o próprio discurso e de forma visível para todos os leitores. 


\section{A função da leitura no jornalismo}

No começo de sua discussão acerca do "Discurso

das Mídias", com o objetivo de alertar sobre 0

terreno em que pretende instaurar o debate,

Charadeau invoca a lógica simbólica - "a maneira

pela qual os indivíduos regulam as trocas

sociais, constroem as representações dos valores

que subjazem suas práticas [...] produzindo

sentido" (2007, p. 16). Ainda que as lógicas

econômica e tecnológica sejam, na sua avaliação,

"incontornáveis", é nesse outro campo que o

debate das mídias, e com ele 0 debate sobre 0

jornalismo, precisa ser instaurado.

0 presente trabalho se filia a essa perspectiva na medida em que se circunscreve à corrente que entende o jornalismo como uma forma de conhecimento do e sobre o mundo, e mais, como uma forma de organização das representações sociais a partir de um discurso particular:

0 campo dos media, como também 0 são os outros, tanto se faz autônomo como dependente. Em outras palavras, ele instaura, ao mesmo tempo em que conforma e redefine, discursos sobre e para a sociedade, ou seja, ele cria e recria práticas sociais discursivas que tanto desejam falar da sociedade como se constituir enquanto saber acerca desta mesma sociedade (RESENDE, 2006, p. 160-161).

Ao narrar o cotidiano, através de filtros como os chamados "critérios de noticiabilidade", ao elaborar seus enunciados a partir da seleção de personagens e pontos de vista (fatos reportados), o jornalismo não apenas anuncia o mundo e narra a sociedade, mas, ao mesmo tempo, a recria, e 0 faz em uma dinâmica relacional, interior a qualquer discurso. Da mesma forma, enquanto cria e recria o mundo social, o jornalismo também recria a si próprio em função do que lhe é externo.

0 jornalismo, entendido como forma de conhecimento e organização do mundo, estrutura-se, em seus diferentes suportes, através do discurso. Seja pela escrita impressa, nas imagens televisivas ou mesmo na instantaneidade das ondas de rádio, o jornalismo narra a realidade através dos sentidos que atribui a ela, como diz Benetti:

\section{0 jornalismo é um modo de conhecimento: ele tanto produz um conhecimento particular sobre os fatos do mundo, quanto reproduz os conhe- cimentos gerados por outros atores [...]. 0 jor- nalismo constrói sentidos sobre a realidade, em um processo de contínua e mútua interferência (2007, p. 110).}

Pode-se entender, assim, que o texto jornalístico é resultado de um complexo diálogo, mesmo que em situação de desigualdade, entre interlocutores específicos, que vão desde a própria instituição jornalística (congregando ainda outros agentes, como os anunciantes), até 0 repórter, suas fontes e, ainda, os leitores. Esse processo - a atividade jornalística - "produz expectativas e intenções para um público e, ao mesmo tempo, deixa-se influenciar por ele para se adequar a seus interesses" (FRANCISCATO, 2005, p. 168). 
Essa dinâmica, associada a outros princípios deontológicos fundadores do jornalismo - como a ideia de verdade e o compromisso com a imparcialidade - forneceram historicamente a essa atividade uma "legitimidade social" (FRANCISCATO, 2005) para produzir uma reconstrução discursiva do mundo, para organizar um relato do cotidiano.

Como não é capaz de noticiar tudo o que acontece, o jornalismo se vale de técnicas, os valores-notícia ${ }^{3}$, a fim de definir o que, das informações que possui, se transformará em notícia. Nesse processo, que também envolve uma série de procedimentos e negociações, o que é dito, e como é dito, passa a ser elaborado levandose em conta diferentes expectativas e interesses que, enfim, serão interpretados no jogo dialógico do discurso jornalístico.

[...] 0 texto é decorrência de um movimento de forças que the é exterior e anterior. 0 texto é parte visivel ou material de um processo altamente complexo que inicia em outro lugar: na sociedade, na cultura, na ideologia, no imaginário (BENETTI, 2007, p. 111).

Esse percurso de construção da notícia, e agora em específico da notícia elaborada com os recursos hipertextuais, tem como resultado um documento digital acessível uniformemente ${ }^{4}$ por qualquer usuário da rede apto a lidar com as especificidades linguísticas, como o idioma, por exemplo.

Sobre o debate do jornalismo como um discurso ${ }^{5}$, é importante salientar sua perspectiva relacional, que deverá acompanhar as demais reflexões deste trabalho e é, segundo Benetti, o norte de todo discurso:

A possibilidade de troca de papéis entre quem enuncia e quem interpreta [...] é condição para que haja discurso. Não é necessário que a troca de papéis seja efetiva ou concretamente possível, mas é necessário que ela possa ser imaginada. Ou melhor: é necessário que os dois sujeitos envolvidos no processo possam compreender a posição de sujeito do outro, além de sua própria (2008).

0 jornalismo, analisado a partir de sua perspectiva discursiva, organiza-se a partir da enunciação, da sua relação com o outro - a sociedade. Como diz Ponte, "a enunciação alarga a linguagem ao seu contexto, em sentido situacional e cultural: de onde se fala, e para quem se fala, o que está para trás e o que está por detrás" (2005, p. 29, grifos do autor). Seguindo essas proposições, passa-se a buscar, nas práticas jornalísticas, o sentido relacional de sua constituição como discurso a partir da busca pela função leitor no jornalismo.

Sobre valores-notícia, ver Wolf (2005) e Traquina (2005).

Há que se levar em conta as diferentes possibilidades de acesso aos dados, relacionadas às estruturas de publicação multiplataforma. Ainda assim, em um sentido discursivo, o acesso a documentos digitais pode ser considerado potencialmente uniforme em determinadas formações sociodiscursivas.

Esse debate já é realizado por pesquisadores como Ponte (2005) e Benetti (2007; 2008), entre outros. 
Com grande importância no desenvolvimento dos estudos sobre jornalismo, o Newsmaking constitui uma tentativa de teorização sobre os processos de produção - as rotinas - e a cultura profissional dos jornalistas. Nesse âmbito de estudos, inscrevem-se desde as tarefas de seleção e edição até a distribuição das informações aos leitores. Uma das suas mais importantes tendências dedica-se a compreender por que determinados acontecimentos se tornam notícia. Ao tratar dos critérios de noticiabilidade ${ }^{6}$, Wolf relaciona, como uma das interferências possíveis sobre o que é noticiável, os critérios relativos ao público, ou seja, "ao papel que reveste a imagem do público, compartilhada pelos jornalistas" (2005, p. 222).

0 autor salienta que se, de um lado, "os jornalistas raramente os conhecem e têm pouca vontade de conhecê-los", é também correto que "a referência e 0 apelo às necessidades, às exigências dos destinatários são constantes, e nas próprias rotinas de produção estão encarnadas assunções explícitas sobre 0 público" (WOLF, 2005, p. 222). Por mais que 0 jornalista, de forma geral, não tenha contato com o público e não receba sua influência de forma direta, os movimentos de construção das notícias, especialmente o que Wolf denomina de "estrutura narrativa" - o processo narrativo das informações que compõe a notícia na estrutura de produção - estão intrinsecamente ligados ao que os jornalistas imaginam ser as expectativas dos leitores. Dessa forma, questões como "0 que o público quer ver?" e "será que o leitor vai entender?" são parte de um processo de construção de uma ideia de leitor.

Mouillaud nos lembra que esse "leitor visado" é aquele que Eco denomina "leitor implícito", "virtual", "modelo"; eles são o que a teoria literária denomina de "destinatário" no campo da comunicação: "uma figura inscrita em filigrana no corpo do jornal" (MOUILLAUD, 1997, p. 174). Na mesma direção, Charadeau (2007) o chama, nas mídias, de "público alvo ideal", que percorre as rotinas produtivas das notícias:

\section{A instância de recepção é portadora de um "conjunto 'impreciso' de valores ético-sociais" e, acrescentemos, "afetivos-sociais", os quais devem ser levados em conta pela instância mi- diática para poder apresentar uma informação mais ou menos de acordo com suas expectati- vas (CHARAUDEAU, 2007, p. 79-80).}

Essa complexa organização de expectativas seria elaborada em um processo subjetivo, um contrato de comunicação que se dá em todos os movimentos midiáticos e leva em conta as rotinas profissionais do jornalismo e os supostos interesses (aqueles imaginados pelo jornalista) dos leitores, além das referências editoriais de organização da comunicação e, ainda mais complexamente, os anunciantes, as fontes, 
outras instituições, etc. Contudo, como observa Laurindo, essa perspectiva se configura, de igual forma, em um movimento de legitimidade que é constituído pelo leitor, no momento mesmo da leitura.

0 gesto de interpretação que vem de fora é [...] uma exterioridade constitutiva simbólica, não empírica, sem separação estanque entre sujeito/objeto, exterioridade/interioridade. $\mathrm{Na}$ sua relação com 0 Outro [0 interdiscurso], 0 autor não poderá dizer coisas sem sentido e, para 0 outro [0 interlocutor], deve dizer coisas com sentido para tal interlocutor determinado, num confronto da história do dizer do autor e de leituras do leitor (LAURIND0, 2008, p. 41).

0 reconhecimento precisa ser mútuo, tanto entre fontes e jornalistas quanto entre esses e o público, e se dá em uma perspectiva de cumprimento de expectativas, consolidando uma dinâmica que, ainda que cercada pela rotinização dos processos de construção das notícias, se estabelece através da leitura (em suas diferentes formas, nos diferentes suportes midiáticos), de forma que no ato de ler "o receptor empossa 0 autor. Nesse momento, atribui-se a posse de ideias a um indivíduo. Querendo encontrar algo para além do gesto de escrita do texto, acaba-se por encontrar um imenso universo de leituras" (LAURIND0, 2008, p. 41).

Mesmo silencioso em seu ato de leitura, 0 leitor completa o "circuito de sentido" do texto jornalístico. Como diz Rodrigues, é o silêncio do público que o torna presente, instituindo-o como uma autêntica instância de interlocução:
[...] 0 silêncio do público não é simples ausência passiva de palavras; é um processo ativo e específico de elaboração do discurso, e é deste silencioso processo de escuta que 0 discurso da mídia recebe o seu princípio, o seu alimento, a sua razão de ser, 0 seu sentido (RODRIGUES, 1997, p. 218).

0 silêncio do público é entendido como a materialização do lugar de ausência que, nos estudos do discurso, remetem ao momento da atribuição de sentido, pelo leitor, ao discurso com o qual ele trava contato. 0 sentido é a constituição fundamental do texto, mas 0 sentido não está no texto. Antes, sim, é nesse "não lugar" que 0 sentido se mostra, e, por isso, é aí o lugar onde 0 texto se realiza.

Assim, ainda que "polarizados", distantes em termos espaço-temporais, o processo de produção das notícias não é um fenômeno isolado, do jornalista, e nem mesmo um processo restrito à negociação do profissional com as fontes e a organização comunicativa. É, além disso, um processo de negociação com o leitor, que o reconhece e legitima discursivamente, a partir desse contrato de comunicação, que é tácito, mas efetivo.

Partindo dessas considerações, como se pode pensar sobre esses aspectos da produção noticiosa na perspectiva de uma linguagem hipertextual digital, na qual o leitor é capaz de argumentar com o jornalista, modificar sua estrutura narrativa, questionar suas escolhas no processo de construção do texto da notícia? Wolf (2005) supõe que, mesmo pensando nos 
interesses e expectativas dos leitores, em um sentido discursivo ou narrativo, o jornalista não tem interesse real de conhecê-los ou de saber o que pensam acerca do trabalho que desenvolve. 0 autor se refere, em seu estudo, ao que se convencionou chamar de "jornalismo tradicional", ou seja, ao jornalismo praticado em suportes anteriores à web, como a televisão e 0 impresso. Mas, poderíamos estender sua preocupação para as rotinas do jornalismo que se desenvolve pelo hipertexto digital?

\section{0 leitor do jornalismo no hipertexto}

Pode-se começar esse debate tomando como ponto de partida a importância do hipertexto para o texto jornalístico na rede. Enquanto linguagem, e enquanto fragmentário, o hipertexto impõe a ação do leitor para a sua efetivação como leitura. É um gesto concreto, como pode ser observado no resumo que Canavilhas (2008) traça para a importância da análise do hipertexto nos estudos sobre o jornalismo na web.

[...] 0 hipertexto é um conceito fundamental em toda a investigação desenvolvida no campo do jornalismo que se faz na web. A sua influência faz-se sentir em todas as áreas do webjornalismo porque interfere com a linguagem, os géneros e com a forma como os receptores se relacionam com os conteúdos através da interactividade. Esta característica é particularmente importante porque marca uma diferença fundamental em relação às notícias da imprensa escrita, não pelo facto de ser hipertextual, mas porque implica uma acção, o clic num link.
A partir do momento em que o receptor desencadeia uma acção, todo o sentido muda, pois 0 utilizador tomou uma decisão em função de uma determinada percepção e pode ter optado por um percurso de leitura diferente do que foi escolhido por outros utilizadores.

A leitura hipertextual é, assim, a materialização daquele lugar de ausência constitutivo do texto. Nessa perspectiva, o leitor age como 0 "ativador do fluxo que institui o espaço navegável" (MACHAD0, 2006, p. 52). Mais do que isso, também é "o ator que interfere no desenvolvimento da narrativa propriamente dita e nas relações com os demais atores" (MACHAD0, 2006, p. 52), ou seja, ele não apenas inaugura o espaço de ausência pela atribuição de sentido, como o preenche e 0 modifica, a partir das características técnicas do hipertexto, e, assim, materializa-se como um coautor, interagindo com o texto em sua materialidade constitutiva.

A interação hipertextual se organiza, de forma mais abrangente, a partir das rotinas de leitura ativa?: são processos de leitura labiríntica e personalização de leitura, processos que envolvem o leitor em suas manifestações opinativas e colaborativas, e mecanismos de ação hipertextual que promovem suas intervenções na organização e elaboração dos conteúdos.

No processo de escritura da narrativa jornalística, as manifestações hipertextuais podem ser 
visualizadas com certa facilidade, especialmente os processos de leitura labiríntica. A inserção de links nas notícias e a consequente organização das informações nos jornais representam um exemplo interessante. Os links, de modo geral, são construções arbitrárias do jornalista ou veículo, que, ao estruturar a narrativa, define as marcas textuais e hipertextuais que serão apresentadas ao leitor como indicações de uma possibilidade de continuação da leitura, de acordo com os seus interesses.

Essa arbitrariedade na oferta de links, por si só, não garante 0 acesso democrático à informação. Em um primeiro momento, porque a estrutura hipertextual dos webjornais tende a ser aquela que Primo (2003) define como "hipertexto potencial", ou seja, fechada à intervenção do leitor. Por mais que o processo de significação aconteça de forma plena com as possibilidades hipertextuais oferecidas no jornal, a produção de sentido nos links deste tipo de documento é ainda delimitada pelas definições prévias do programador (jornalista/veículo), que indica ao navegador hipertextual as possibilidades de interconexão e leitura.

Um segundo e importante aspecto relacionase à estrutura hipertextual estabelecida pelo veículo para o site. Neste caso, essa organização se dá tanto em relação aos recursos tecnológicos (aqueles que favoreceram o desenvolvimento das novas gerações do hipertexto), quanto é uma definição de política institucional, por assim dizer. De forma geral, os links efetivamente construídos pelo jornalista nas matérias "apontam para textos diversos, mas finitos, passíveis de circulação no domínio discursivo do jornal em questão" (CAVALCANTE, 2005, p. 166). A autora prossegue:

[...] os links seriam as representações dessas redes que 0 autor propositalmente apresenta ao leitor, como estratégia de marcar seu próprio percurso enquanto autor, seu estilo, sua história, seu lugar de autoria, e delineando que caminhos o leitor pode perseguir nesta(s) sua(s) leitura(s). (CAVALCANTE, 2005, p. 167).

Essa é uma prática relativamente comum nos textos dos webjornais, circunscrevendo a hipertextualidade a um circuito limitado de possibilidades, geralmente motivadas pelos interesses institucionais do veículo. A utilização dos links para a construção do recurso memória, uma característica da escrita nos webjornais, demonstra com certa facilidade a perspectiva deste circuito hipertextual. A rotina de "linkar" apenas para endereços dentro do próprio site do jornal não apenas limita o processo de circulação dos discursos da rede, como inscreve 0 leitor em uma programação sempre reduzida de possibilidades de leitura, o que significa uma ruptura com os conceitos próprios do hipertexto, como a não hierarquização e não linearidade.

Um terceiro elemento a ser observado se inscreve na ideia de reposicionamento do hipertexto, em seu funcionamento no discurso. Da mesma forma que algumas palavras são selecionadas 
pelo autor para a criação de nós, links, entre matérias correlativas, ou mesmo para indicar uma fonte no ciberespaço ${ }^{8}$, podem ser utilizadas para referenciar qualquer coisa na rede, visto que não há nenhuma ligação anteriormente constituída entre 0 que é escrito e o que é linkado. De uma forma geral, conteúdos semelhantes não precisam, necessariamente, ser vinculados e há total liberdade do programador quanto ao que será apontado em determinado link.

Isso significa que é possível utilizar o hipertexto como ferramenta de publicidade, a fim de aumentar e, especialmente, diversificar os espaços publicitários nos sites. Uma das formas mais comuns de programação desse tipo consiste em apontar com o link um endereço como qualquer outro (uma matéria relacionada no mesmo site, por exemplo) e utilizar um comando específico para que, antes do clique, 0 internauta veja surgir em sua tela uma pequena ' $h$ int $^{\text {’9 }}$, um balão explicativo contendo uma mensagem publicitária ${ }^{10}$.

A configuração da escrita jornalística hipertextual ainda deve considerar a utilização de recursos multimidiáticos e a vinculação de bases de dados aos conteúdos noticiados. A utilização de imagens, vídeos, áudios e infográficos se realiza a partir da prática hipertextual, e a indicação de conteúdos multimídia deve receber atenção. Esses instrumentos narrativos são estruturas hipertextuais de leitura, que favorecem a narrativa jornalística a partir de suas características específicas.

Todos esses aspectos, e com certeza não apenas eles, constituem considerações práticas acerca das problemáticas da construção do discurso jornalístico com a linguagem hipertextual. Mas além do debate acerca da leitura labiríntica, outros mecanismos começam a ser visualizados na estrutura dos jornais online e sugerem ambientes de colaboração entre profissionais e leitores.

Entre as manifestações hipertextuais relacionadas a essas práticas, surgem ambientes de debate e informação, em que o leitor passa a interferir materialmente no discurso, com comentários e opiniões. Nesses contextos, há uma alteração no processo de construção dos discursos, visto que a participação através de comentários se apresenta como uma continuação do próprio texto, e suas opiniões passam a figurar naquele universo textual particular como complementos de sentido do discurso inicial.

Para uma discussão mais aprofundada da questão do uso do ciberespaço como fonte para os jornalistas, sugere-se a leitura de Machado (2003).

Hint, do inglês 'dica', é utilizado no jargão informático para referenciar uma propriedade da linguagem hipertextual que permite a inclusão de informações adicionais, em pequenos balões informativos, sobre o texto de um link.

A prática da publicidade hipertextual precisa ser debatida com ênfase, visto que além do movimento dialógico natural do texto, os nós hipertextuais têm a propriedade de sugerir outras significações - e nem sempre a proposta publicitária está marcadamente explicitada, o que pode provocar uma quebra no contrato de leitura, que também aqui se efetiva, com o leitor/interagente. 
Nos veículos jornalísticos, essas manifestações se organizam, por exemplo, nos blogs e nos comentários em notícias online, e que configuram o que Primo e Recuero (2003) definem como "hipertexto colagem". Nelas, a relação entre jornalista e leitor, agora transformada em relação entre interagentes, tem uma ligação discursiva dialógica e coletiva, colaborativa. Nos casos em que a postagem ou notícia é resultado de um anterior processo de negociação e debate, essa característica fica ainda mais clara. Jornalistas e leitores se aproximam pelo debate, e as negociações estabelecidas a partir dos ambientes de comentários podem gerar novas intervenções dos profissionais ${ }^{11}$.

Ainda assim, na maioria dos blogs jornalísticos, e especialmente nas notícias no corpo dos jornais, esse processo de retorno do profissional depois da postagem principal não acontece - 0 que, em si, não significa que o processo de escrita coletiva esteja comprometido.

Essas notas, representadas pelas opiniões e comentários das pessoas formam intrincadas trilhas hipertextuais dentro da própria Rede, que são constantemente modificadas e trabalhadas pelos autores que lerão o texto em seguida. Cada internauta pode, portanto, observar as associações dos outros leitores e colocar também as suas. Trata-se, deste modo, de uma construção coletiva (PRIM0; RECUERO, 2003, p. 59).
A partir das cascatas de comentários, os leitores têm acesso a mais conteúdos, informações e opiniões dos colaboradores, o que, pelo menos virtualmente, pode gerar modificações de sentido no conteúdo central da notícia ou postagem.

Mas manifestações colaborativas mais específicas, como o envio de notícias para os espaços de "jornalismo colaborativo" dos jornais online, também são entendidas como manifestações hipertextuais do leitor, e apresentam certa liberdade de ação (na constituição do texto, por exemplo), ainda que limitadas pelas dinâmicas de verificação e publicação dos conteúdos, de responsabilidade dos veículos que, de forma geral, conferem as informações, em alguns casos editam 0 texto e publicam a notícia no local e com o destaque que julgarem necessários.

Essas considerações, apesar de não esgotarem as possibilidades de análise do hipertexto no jornalismo, marcam as especificidades da escritura hipertextual e salientam a possibilidade de emergência de manifestações colaborativas entre profissionais e leitores no jornalismo online. 0 hipertexto é a base constitutiva da web e, por isso, suas características implicam adaptações à prática informacional. A presença material do leitor, inserindo-se na formulação narrativa das notícias, tornando- 
se um produtor de conteúdos, participando ativamente da construção das notícias, mesmo que opinativamente, pode demonstrar uma modificação estrutural na relação com os jornalistas e com o jornalismo.

\section{Considerações Finais}

Entre as principais implicações do uso da linguagem hipertextual no jornalismo está uma significativa alteração nos modos ou modelos de publicação dos conteúdos que, agora fragmentados, em virtude da velocidade de publicação e da dinâmica de atualização de informações, transformam não apenas a forma de construção, mas, e especialmente, as formas de leitura desses conteúdos.

Neste trabalho, procurou-se destacar essas formas de organização dos discursos pelo estabelecimento de uma ideia de função leitor, de forma a salientar as alterações promovidas pelo surgimento das dinâmicas hipertextuais no âmbito do jornalismo. 0 hipertexto digital modifica as negociações com os discursos, com as atividades de linguagem, com os sujeitos discursivos. Alteram-se as estruturas de configuração dos textos e, mesmo, as relações que eles estabelecem entre os sujeitos em relação no processo discursivo. Considerando os aspectos linguísticos do hipertexto, tratou-se dos mecanismos de organização discursiva e das formas de materialização dialógica dos textos online e suas implicações na reorganização do discurso jornalístico e das manifestações de leitura ativa.
Essas atividades dos leitores, inscrevendo-se em movimentos de coautoria, demonstram que a leitura se materializa, no hipertexto, como um procedimento: informações fragmentadas e em constante atualização exigem leitores ágeis, capazes de cruzar dados, de relacionar informações e, especialmente, de pesquisar conteúdos em fontes diversas. Se um texto impresso interpõe seu suporte como limitador da materialização da coautoria imediata ou, ao menos, a torna subjetiva à leitura, no universo hipertextual essas características podem se tornar, efetivamente, as regras de manifestação autoral, nas quais leitores buscam a ressignificação dos conteúdos fragmentados a partir de sua inscrição em rotas de navegação e hiperconexões, na interação com outros sujeitos de discurso, sejam eles outros leitores ou mesmo jornalistas.

\section{Referências}

BENETTI, Marcia. A ironia como estratégia discursiva da revista Veja. In: ENCONTRO ANUAL DE ASSOCIAÇÃO NACIONAL DOS PROGRAMAS DE PÓS-GRADUAÇÃO EM COMUNICAÇÃO, 16., 2007, Curitiba. Anais... Curitiba: Compós, 2007. CD-ROM. 0 jornalismo como gênero discursivo. Revista Galáxia, São Paulo, v. 15, p. 13-28, 2008. Disponível em: $<$ http://www.revistas.univerciencia. org/index.php/galaxia/article/view/5730/5187>. Acesso em: 25 ago. 2008.

BRONCKART, Jean-Paul. Atividades de linguagem, textos e discursos: por um interacionismo sociodiscursivo. 2. ed. São Paulo: EDUC, 1999. 
CANAVILHAS, João. Hipertexto e recepção de notícias online. Biblioteca Online de Ciências da Comunicação, 2008. Disponível em: <http://www.bocc. ubi.pt/pag/canavilhas-joao-hipertexto-e-recepcaonoticias-online.pdf>. Acesso em: 02 dez. 2008.

CAVALCANTE, Marianne C. B. Mapeamento e produção de sentido: os links no hipertexto. In: MARCUSCHI, Luiz A; XAVIER, Antônio C. (orgs.). Hipertexto e gêneros digitais. 2.ed. Rio de Janeiro: Lucerna, 2005. p. 163-169.

CHARADEAU, Patrick. Discurso das mídias. São Paulo: Contexto, 2007.

CHARTIER, Roger. A aventura do livro: do leitor ao navegador. São Paulo: UNESP; Imprensa Oficial do Estado de São Paulo, 1999.

FOUCAULT, Michel. A ordem do discurso. 10. ed. São Paulo: Loyola, 2004.

\section{FRANCISCATO, Carlos Eduardo. A fabricação do} presente: como o jornalismo reformulou a experiência do tempo nas sociedades ocidentais. São Cristóvão: Universidade Federal de Sergipe, 2005.

LANDOW, George. Hypertext 3.0. Baltimore: Johns Hopkins, 2006.

LAURIND0, Rosemeri. Jornalismo em três dimensões (singular, particular e universal): autor-jornalista e autor-marca. Blumenau: Edifurb, 2008.

MACHAD0, Elias. 0 ciberespaço como fonte para os jornalistas. Florianópolis: Calandra, 2003.

0 jornalismo digital em base de dados.

Florianópolis: Calandra, 2006.

MOUILLAUD, Maurice. Posturas do leitor. In: PORTO, Sergio D. 0 jornal: da forma ao sentido. Brasília: Paralelo 15, 1997. p. 173-190.

PONTE, Cristina. Para entender as notícias: linhas de análise do discurso jornalístico. Florianópolis: Insular, 2005.
PRIM0, Alex. Quão interativo é o hipertexto? : Da interface potencial à escrita coletiva. Fronteiras: estudos midiáticos, São Leopoldo, v. 5, n. 2, p. 125142, 2003.

PRIMO, Alex F. T.; RECUER0, Raquel C. Hipertexto cooperativo: uma análise da escrita coletiva a partir dos blogs e da Wikipédia. Revista da FAMECOS, Porto Alegre, n. 23, p. 54-63, dez. 2003.

RESENDE, Fernando. 0 jornalismo e a enunciação: perspectivas para um narrador-jornalista. In: LEMOS, André; BERGER, Christa; BARBOSA, Marialva (orgs.) Narrativas midiáticas contemporâneas. Porto Alegre: Sulina, 2006. p. 160-180.

RODRIGUES, Adriano D. Delimitação, natureza e funções do discurso midiático. In: MOUILLAUD, Maurice; PORTO, Sergio D. 0 jornal: da forma ao sentido. Brasília: Paralelo 15, 1997. p. 217-233.

SOUZA, Pedro de. No excesso de leitura a deflação de leitor. In: ORLANDI, Eni P. (org.). A leitura e os leitores. 2.ed. Campinas: Pontes, 2003. p. 127-137.

TRAQUINA, Nelson. Teorias do Jornalismo: porque as notícias são como são. Volume I. 2. ed. Florianópolis: Insular, 2005.

WOLF, Mauro. Teorias das comunicações de massa. 2. ed. São Paulo: Martins Fontes, 2005. 
The reader as a meaning constitutive absence in Journalism: the reorganization of journalistic discourse in digital hypertext

\section{Abstract}

This paper discusses the reorganization of the journalistic discourse considering the materialization of an active reading process on digital journalism, from hypertext. We consider also the implications of the discursive function while reading the discourse, which is stated in a dialogical movement to give meaning to a text. Starting with a brief overview of the reader's position in the journalistic text construction dialectic and considering the inclusion of new language derived from hypertextual programming logic, it aims to discuss the forms of manifestation of reading activities, the structure protruding digital journalism.

\section{Keywords}

Journalism. Hypertext. Reading. Interaction.

\section{El lector como ausencia constitutiva de sentido en Periodismo: la reorganización del discurso periodístico en el hipertexto digital}

\section{Resumen}

El texto trata de discutir la reorganización del discurso periodístico considerando un proceso de materialización de una lectura activa en el periodismo digital, a partir del hipertexto. Consideramos también las implicaciones de la función discursiva, mientras que una función del discurso, que se afirma en un movimiento dialógico de atribución de sentido al texto. Comenzando con una breve reseña de la posición del lector en la dialéctica de la construcción del texto periodístico y considerando el registro de nuevas lógicas literales sucedidas de la programación hipertextual en Internet, se piensa para discutir las formas de manifestación de las acciones de la lectura, salientes en la estructura periodística digital.

\section{Palabras clave}

Periodismo. Hipertexto. Lectura. Interacción. 


\section{Expediente}

A revista E-Compós é a publicação científica em formato eletrônico da Associação Nacional dos Programas de Pós-Graduação em Comunicação (Compós). Lançada em 2004, tem como principal finalidade difundir a produção acadêmica de pesquisadores da área de Comunicação, inseridos em instituições do Brasil e do exterior.
E-COMPÓS I www.e-compos.org.br I E-ISSN 1808-2599

Revista da Associação Nacional dos Programas de Pós-Graduação em Comunicação. Brasília, v.12, n.2, maio/ago. 2009

A identificação das edições, a partir de 2008 passa a ser volume anual com três números.

\section{CONSELHO EDITORIAL}

\section{Afonso Albuquerque}

Universidade Federal Fluminense, Brasil

Alberto Carlos Augusto Klein

Universidade Estadual de Londrina, Brasi

Alex Fernando Teixeira Primo

Universidade Federal do Rio Grande do Sul, Brasi

\section{Alfredo Vizeu}

Universidade Federal de Pernambuco, Brasil

Ana Carolina Damboriarena Escosteguy

Pontifícia Universidade Católica do Rio Grande do Sul, Bras

Ana Silvia Lopes Davi Médola

Universidade Estadual Paulista, Brasil

André Luiz Martins Lemos

Universidade Federal da Bahia, Brasil

Ângela Freire Prysthon

Universidade Federal de Pernambuco, Brasil

Antônio Fausto Neto

Universidade do Vale do Rio dos Sinos, Brasil

Antonio Carlos Hohlfeldt

Pontifícia Universidade Católica do Rio Grande do Sul, Brasil

Arlindo Ribeiro Machado

Universidade de São Paulo, Brasil

César Geraldo Guimarães

Universidade Federal de Minas Gerais, Brasil

Cristiane Freitas Gutfreind

Pontifícia Universidade Católica do Rio Grande do Sul, Brasil

Denilson Lopes

Universidade Federal do Rio de Janeiro, Brasil

Eduardo Peñuela Cañizal

Universidade Paulista, Brasi

Erick Felinto de Oliveira

Universidade do Estado do Rio de Janeiro, Brasil

Francisco Menezes Martins

Universidade Tuiuti do Paraná, Brasil

Gelson Santana

Universidade Anhembi/Morumbi, Brasi

Hector Ospina

Universidad de Manizales, Colômbia

leda Tucherman

Universidade Federal do Rio de Janeiro, Brasil

Itania Maria Mota Gomes

Universidade Federal da Bahia, Brasil

Janice Caiafa

Universidade Federal do Rio de Janeiro, Brasil

Jeder Silveira Janotti Junior

Universidade Federal da Bahia, Brasil

\section{João Freire Filho}

Universidade Federal do Rio de Janeiro, Brasil

John DH Downing

University of Texas at Austin, Estados Unidos

José Luiz Aidar Prado

Pontifícia Universidade Católica de São Paulo, Brasil

José Luiz Warren Jardim Gomes Braga

Universidade do Vale do Rio dos Sinos, Brasil

Juremir Machado da Silva

Pontifícia Universidade Católica do Rio Grande do Sul, Brasil

Lorraine Leu

University of Bristol, Grã-Bretanha

Luiz Claudio Martino

Universidade de Brasília, Brasil

Maria Immacolata Vassallo de Lopes

Universidade de São Paulo, Brasil

Maria Lucia Santaella

Pontifícia Universidade Católica de São Paulo, Brasil

Mauro Pereira Porto

Tulane University, Estados Unidos

Muniz Sodre de Araujo Cabral

Universidade Federal do Rio de Janeiro, Brasil

Nilda Aparecida Jacks

Universidade Federal do Rio Grande do Sul, Brasil

Paulo Roberto Gibaldi Vaz

Universidade Federal do Rio de Janeiro, Brasil

Renato Cordeiro Gomes

Pontifícia Universidade Católica do Rio de Janeiro, Brasil

Ronaldo George Hela

Universidade do Estado do Rio de Janeiro, Brasil

Rosana de Lima Soares

Universidade de São Paulo, Brasil

Rossana Reguillo

Instituto Tecnológico y de Estudios Superiores do Occidente, México

Rousiley Celi Moreira Maia

Universidade Federal de Minas Gerais, Brasil

Sebastião Carlos de Morais Squirra

Universidade Metodista de São Paulo, Brasil

Simone Maria Andrade Pereira de Sá

Universidade Federal Fluminense, Brasil

Suzete Venturelli

Universidade de Brasília, Brasil

Valério Cruz Brittos

Universidade do Vale do Rio dos Sinos, Brasil

Veneza Mayora Ronsini

Universidade Federal de Santa Maria, Brasil

Vera Regina Veiga França

Universidade Federal de Minas Gerais, Brasil
COMISSÃO EDITORIAL

Ana Gruszynski I Universidade Federal do Rio Grande do Sul, Brasil Felipe da Costa Trotta I Universidade Federal de Pernambuco, Brasil Rose Melo Rocha I Escola Superior de Propaganda e Marketing, Brasil

\section{CONSULTORES AD HOC}

Aníbal Francisco Alves Bragança I Universidade Federal Fluminense, Brasil Benjamim Picado I Universidade Federal da Bahia, Brasil

Carlos Eduardo Franciscato I Universidade Federal de Sergipe, Brasi

Christa Liselote Berger I Universidade Vale do Rio dos Sinos, Brasil

Gisela Castro I Escola Superior de Propaganda e Marketing, Brasil

Luciana Pellin Mielniczuk I Universidade Federal de Santa Maria, Brasi

Marcia Benetti I Universidade Federal do Rio Grande do Sul, Brasil

Paulo Cunha Carneiro Filho I Universidade Federal de Pernambuco, Brasil

Raquel Recuero I Universidade Católica de Pelotas, Brasil

REVISÃO DE TEXTO E TRADUÇÃO I Everton Cardoso

EDITORAÇÃO ELETRÔNICA I Raquel Castedo
COMPÓS I www.compos.org.br

Associação Nacional dos Programas de Pós-Graduação em Comunicação

Presidente

Itania Maria Mota Gomes

Universidade Federal da Bahia, Brasil

itania@ufba.br

Vice-presidente

Julio Pinto

Pontifícia Universidade Católica de Minas Gerais, Brasil

juliopinto@pucminas.br

Secretária-Geral

Ana Carolina Escosteguy

Pontifícia Universidade Católica do Rio Grande do Sul, Brasil

carolad@pucrs.br 